\title{
Endogenous Market Structures and International Trade
}

\author{
Federico Etro \\ Ca' Foscari University of Venice
}

First Draft: June 2010

\begin{abstract}
I extend the endogenous market structures approach to international trade theory and policy. When markets are characterized by strategic interactions and endogenous entry, opening up to trade decreases the price level, and increases concentration and the production of each firm, with a positive competition effect on welfare. With endogenous entry of foreign firms in the domestic market it is optimal to set a positive import tariff decreasing in the ratio between entry costs and market size. With endogenous entry of international firms in an integrated market, the optimal subsidy to domestic production is always positive and independent from the relative size of the domestic market. Implications for multinationals engaged in FDIs, indirect trade promotion and the lobbying are also analyzed.
\end{abstract}

\section{Keywords}

Endogenous entry, gains from trade, import tariff, production subsidy.

\section{JEL Codes}

F12, F13.

Address for correspondence:

Federico Etro

Department of Economics Ca’ Foscari University of Venice Cannaregio 873, Fondamenta S.Giobbe 30121 Venezia - Italy Phone: (++39) 3294464955 Fax: (++39) 0412349176 e-mail: fetro@intertic.org

This Working Paper is published under the auspices of the Department of Economics of the Ca' Foscari University of Venice. Opinions expressed herein are those of the authors and not those of the Department. The Working Paper series is designed to divulge preliminary or incomplete work, circulated to favour discussion and comments. Citation of this paper should consider its provisional character.

The Working Paper Series
is availble only on line
(www.dse.unive.it/pubblicazioni)
For editorial correspondence, please contact:
wp.dse@unive.it

Department of Economic

Ca' Foscari University of Venice

Cannaregio 873, Fondamenta San Giobbe

30121 Venice Italy

Fax: ++390412349210 
In the traditional theories of trade, the gains from trade are associated with international specialization or with the availability of new varieties of goods. In particular, Krugman (1980) has introduced monopolistic competition in the trade literature emphasizing the endogenous increase in the number of products purchased at a constant price after a country opens up to trade. The normative theory of trade has mainly emphasized the optimality of import tariffs and (typically) taxes on domestic exportables either to improve the terms of trade (in the neoclassical theory) or for profit shifting reasons (Eaton and Grossman, 1986). All these approaches neglect a fundamental consequence of trade, the competitive impact of international entry on the strategic interactions between firms and on the resulting international prices. ${ }^{1}$ This leads to a separate source of gains from trade, which partially crowds out the traditional one, and to different and sometimes opposite conclusions on the optimal trade policy for domestic, foreign and intergated markets. However, in spite of the pathbreaking contribution by Brander (1981) and Brander and Krugman (1983), the main implications of the endogenous market structures (EMSs) approach have not been investigated in a systematic way: not by chance, leading international trade economists (as Neary, 2010) talk about the existence of "two and a half theories of trade." ${ }^{2}$

The analysis of strategic interactions emphasizes that the gains from trade are mainly associated with a reduction in the prices due to international competition. This separate source of gains from trade represents a sort of folk theorem in international trade theory - see for instance Krugman (1979), Brander and Krugman (1983) or more recently Lahiri and Ono (1995) and Peretto (2003) but its theoretical, empirical and welfare implications have not been fully analyzed. We present a general model of the impact of trade integration on the structure of markets with strategic interactions and endogenous entry and discuss in detail the case of homogenous goods and linear demand and the case of isoelastic preferences à la Krugman (1980). As a first impact, trade integration strengthens competition and induces a generalized reduction of the prices, which is a primary source of gains from trade due to the competition effect. As

\footnotetext{
${ }^{1}$ The neoclassical approach and the monopolistic competition approach do not consider strategic interactions and most of the strategic trade literature takes them into account but neglects endogenous entry.

${ }^{2}$ As well known, the analysis of EMSs in industrial organization has a wide tradition which goes back at least to the work of Sutton (1991) and has been recently used to analyze multiple issues, including the role of strategic investments (Etro, 2006) and exogenous shocks (Anderson et al., 2010), incentive and financial contracts (Etro, 2010a,b), investment in R\&D (Kováč et al., 2010; Erkal and Piccinin, 2010), growth (Peretto, 1996), business cycle theory (Devereux, Head and Lapham, 1996; Etro and Colciago, 2010) and more. For important dynamic analysis of trade issues see the recent works of Melitz (2003) and Atkeson and Burstein (2008, 2010).
} 
a second impact, the price reduction creates a negative feedback on profitability which crowds out the expansion of the number of produced varieties and leads to business destruction at the local level: this reduces (or eliminates in case of homogenous goods) the traditional gains from variety $\grave{a}$ la Krugman and provides an empirical discriminant between the monopolistic competition approach and the EMS approach (tested in the Appendix with results in favor of the latter). As a third impact, after trade integration the equilibrium market structure is characterized by a larger production of each surviving firm: this increase in concentration is welfare enhancing because reduces the expenditure in fixed costs, which creates another source of gains from trade. In spite of these gains from trade associated with price reduction and beneficial concentration, the market structure remains inefficient because of the stategic interactions (Mankiw and Whinston, 1986). In particular, there is a tendency toward excessive mark ups and entry which opens the door to new roles for trade policy.

The analysis of international EMSs has important normative implications, which are address here, as far as we know, for the first time. When a domestic firm is facing endogenous entry of international firms, the optimal tariff balances the benefits from profit shifting (still present in spite of free entry) and tariff revenues and the cost of the price increase: we derive the optimal tariff (with a closed form solution for a Cournot model with linear demand) and show that this is decreasing in the ratio between size of the economy and fixed entry cost. The main role of the tariff is to decrease entry of foreign firms, which reduces the production inefficiency associated with the free trade equilibrium: this creates space for increasing the market share and the profits of the domestic firm (compared to zero profits in case of free trade), while collecting also some tariff revenue. These domestic benefits are larger when the fixed cost is high relative to the size of the market because in this case the production inefficiency associated with free trade is high.

Radical changes from the traditional results occur when a domestic firm is active in an integrated market and the government can subsidize its production (the remaining extreme case of a third market is analyzed in the companion paper, Etro, 2011). ${ }^{3}$ Consider a market including domestic and foreign consumers: in case of an exogenous number of foreign competitors the optimal policy can be a tax or a subsidy to domestic production, depending on the form of competition (in prices or in quantities) and on the size of the domestic market relative to the integrated one, but with endogenous entry of international firms, the optimal policy is always a positive subsidy to domestic production, independent from the size of the domestic country. The intuition relies on the fact that, in

\footnotetext{
${ }^{3}$ Our current analysis applies when export subsidies are forebidden, but subsidies to the entire domestic production are possible. This is exactly what happens under the WTO rule.
} 
an integrated market with endogenous entry, the domestic consumer surplus is indipendent from the domestic strategies and policies and remains anchored to the entry process which drives profits to zero for the international producers. Nevertheless, the entry process is inefficient, and the domestic firm can appropriate some rents when forced to act aggressively in the market, for instance through a production subsidy. Since profits are gained worldwide, the optimal subsidy depends on the size of the integrated market, but not on the size of the domestic one.

The investigation of EMSs in international trade theory has a number of precursors. The so-called "reciprocal dumping" model started with Brander (1981) and Brander and Krugman (1983) is the pathbreaking work in the analysis of strategic interactions in intra-industry trade, but it marginally considered the case of endogenous entry and was developed in a Cournot model with homogenous goods rather than in the general framework analyzed here. ${ }^{4}$ Horstmann and Markusen (1992) focus on the entry decisions of just two multinationals in two segmented national markets with competition in quantities and fixed costs of entry at the firm and plant level, characterizing how technological conditions and trade policy induce switching between equilibria with a single firm or with two firms. More recently, foreign direct investment in the presence of EMSs has been studied by De Santis and Stahler (2004) who endogenize the number of national and multinational firms active in two countries, and by Markusen and Stähler (2010) who investigate the impact of greenfield investments by multinationals and cross-border acquisitions in markets with endogenous entry. Finally, the Melitz (2003) model of trade with heterogenus firms has been extended to strategic interactions by van Long et al. (2009), but welfare and policy isses have not been addressed yet. The introduction of fully fledged EMSs in the literature on trade policy has been rather slow, since most of the many initial contributions have been constantly focused on duopoly cases - only Venables (1985) and Horstmann and Markusen (1986) analyzed trade policy for international markets with free entry of all firms, but they did not consider trade policy for a domestic firm facing free entry of international competitors. In a companion paper (Etro, 2011) I have analyzed strategic export promotion in a third market with EMSs, applying the same principles to the analysis of export subsidies, R\&D subsidies and competitive devaluations. Contrary to that, here I study the optimal trade policy for a domestic firm facing endogenous entry in a domestic market and in an integrated market.

The paper is organized as follows. Section 1 introduces general models of EMSs. Section 2 extends the linear demand model and the Krugman model to

\footnotetext{
${ }^{4}$ Lahiri and Ono (1995) have investigated a 2x2x2 model with Cournot competition and endogenous entry in one sector, but limiting the analysis to the case of homogenous goods.
} 
strategic interactions with endogenous entry and characterizes the gains from trade associated with the competition effect. Section 3 is about trade policy for the domestic market. Section 4 is about trade policy for an integrated market. Section 5 develops few new applications. Section 6 concludes.

\section{A general model of international EMSs}

In this paper we analyze endogenous market structures that belong to a general class introduced in Etro $(2006,2011)$. Consider a market whose size can be measured with the number of identical consumers $S$, and where every firm bears a fixed entry cost $F$. Assume that each firm chooses a strategic variable $x(i)$ delivering the net profit function:

$$
\pi_{i}=S \Pi\left[x(i), \beta_{i}, \mu_{i}\right]-F
$$

where the gross profit per consumer $\Pi\left[x(i), \beta_{i}, \mu_{i}\right]$ depends on the aggregate statistics of the strategies of the other firms $\beta_{i}=\sum_{j \neq i} h(x(j))$ for a positive and increasing function $h(x)$, and on a firm specific variable $\tau_{i}$, which may be a trade cost or a policy variable. We only assume that profits are quasiconcave in $x(i)$, decreasing in $\beta_{i}$ and increasing in $\mu_{i}{ }^{5}$ Standard models of quantity competition (with $x(i)$ as the output level of firm $i$ ) and price competition (with $x(i)$ as the inverse of the price level) generate profit functions that can be described as above: our examples will be based on the cases of linear demand and Dixit-Stiglitz demand.

In the absence of firm specific heterogeneity $\left(\mu_{i}=\mu\right.$ for any $\left.i\right)$, a general characterization of Nash equilibria with endogenous entry is straightforward. In a symmetric equilibrium, the first order condition and the endogenous entry condition define the equilibrium strategies $x$ and number of firms $n$ as follows:

$$
\Pi_{1}[x,(n-1) h(x), \mu]=0 \text { and } \Pi[x,(n-1) h(x), \mu]=\left(\frac{S}{F}\right)^{-1}
$$

It can be easily verified that an increase in the ratio between size of the economy and fixed entry cost $S / F$ has ambiguous effects on $x$ and increases the number of firms $n$. Moreover, as we will see in Section 2, in standard models it also strengthens competition, reduces prices and increases less than proportionally the number of firms. This is a crucial effect that we expect from opening up to trade with countries of size $S^{*}$ to create a market of size $\bar{S}=$

\footnotetext{
${ }^{5}$ We allow $\Pi_{13}$ to be positive or negative: in the first case, a policy increases marginal profitability. All forms of trade costs, subsidies or tariffs under quantity and price competition imply $\Pi_{13}>0$, but other indirect forms of export promotion can be characterized by $\Pi_{13}<0$.
} 
$S+S^{*}$ : integration tends to reduce the international mark ups and the number of firms in each country, while increasing less than proportionally the total number of firms active (and varieties produced) for the integrated market. We provide some empirical evidence for this implication (against the implications of the monopolistic competition approach) in the Appendix.

Let us assume, as it holds in a wide class of models nested in our specification (Anderson et al., 2010), that the consumer surplus of a representative agent $u$ is an increasing function of the aggregate statistics $\sum_{j=1}^{n} h(x(j))$. Therefore, total consumer surplus $U$ for $S$ agents can be written as:

$$
U=S u\left[\sum_{j=1}^{n} h(x(j))\right]
$$

For instance, under competition in quantities consumer surplus depends on total production when the goods are homogenous and on a weighted sum of the production levels with standard forms of product differentiation (as those derived from CES preferences), and under competition in prices with standard demand functions consumer surplus is decreasing in a properly defined price index.

Since profits are zero in a symmetric equilibrium with endogenous entry, welfare corresponds to the consumer surplus $S u[n h(x)]$. This will be increasing in the relative size of the integrated economy because of two effects: the increase in the number of firms $n$ increases the number of goods produced (traditional gains from variety), and stronger competition due to market integration reduces the prices and increases the consumption of each variety $x$ (gains from competition). However, the endogenous market structure is characterized by an inefficient allocation of production, typically due to excessive prices and entry: this opens the door to a new role for trade policy.

Our simple model allows us to evaluate the impact of structural changes or policy interventions for a domestic, foreign and integrated markets. Let us consider a general market with a single domestic firm whose profitability is affected by a specific parameter $\mu$, and many foreign firms whose entry is endogenous and possibly affected by a common parameter $\mu^{*}$. Let us denote with an asterisk the variables and the profit functions of the foreign firms. In the absence of prohibitive trade policies, the equilibrium strategies of the domestic firm $x$ and of the foreign firms $x^{*}$, and the total number of active firms $n$ must satisfy the optimality and endogenous entry conditions:

$$
\begin{gathered}
\Pi_{1}\left[x,(n-1) h\left(x^{*}\right), \mu\right]=0 \\
\Pi_{1}^{*}\left[x^{*},(n-2) h\left(x^{*}\right)+h(x), \mu^{*}\right]=0
\end{gathered}
$$




$$
\Pi^{*}\left[x^{*},(n-2) h\left(x^{*}\right)+h(x), \mu^{*}\right]=\left(\frac{S}{F}\right)^{-1}
$$

It follows (from the last two conditions) that the strategy of the foreign firms $x^{*}$ depends on $\mu^{*}$, but not on $\mu$. Most important, even the aggregate statistics perceived by the foreign firms, $\beta^{*}=(n-2) h\left(x^{*}\right)+h(x)$, depends on $\mu^{*}$ but not on $\mu$. As a consequence also the consumer surplus is independent from $\mu$, because the aggregate statistics $\sum_{j=1}^{n} h(x(j))=\beta^{*}+h\left(x^{*}\right)$ depends on $\mu^{*}$, but does not change with $\mu$. On the other hand, the strategy of the domestic firm $x$ and the number of entrants $n$ depend on both the structural or policy parameters, which may affect the profits of the domestic firm. We can informally summarize our result as follows:

Theorem. Under endogenous market structures with competition in quantities or prices, any structural or policy shift affecting the profitability of a domestic firm is not going to change the domestic consumers surplus and the strategies of the foreign firms, but changes their number and the profits of the domestic firm.

Finally, notice that a change in the ratio between size of the economy and fixed entry cost $S / F$ has the same impact as before on the equilibrium system for the strategies of the foreign firms $x^{*}$, their aggregate statistics $\beta^{*}$ and, as a consequence, for consumer surplus. This general framework can be used to analyze the impact of trade in specific models and the impact of structural changes between domestic and foreign firms and changes in the trade policy for different markets: a third market, as analyzed in the companion paper (Etro, 2011), a domestic market and an international integrated market (with both domestic and foreign consumers), as analyzed here.

First of all, let us interpret the market as a domestic market of size $S$ where the government can choose an import tariff $\mu^{*}=t$ and a production subsidy $\mu=\tau$. Assuming that the subsidy is a pure transfer of domestic resources and the tariff revenue function $R(\cdot)$ is proportional to the aggregate statistics of the foreign strategies (as in standard cases), welfare can be written as:

$W(\tau, t)=S u\left[(n-1) h\left(x^{*}\right)+h(x)\right]+S \Pi\left[x,(n-1) h\left(x^{*}\right), 0\right]-F+R\left[t(n-1) h\left(x^{*}\right)\right]$

where the endogenous variables derive from the equilibrium characterized above and therefore from both policy tools, but the subsidy does not affect consumer surplus in line with our Theorem. The optimal tariff balances the benefits from profit shifting and tariff revenues with the cost of the price increase. In Section 3 we derive the optimal policy in a special case of a linear Cournot model: as 
we will see, the optimal tariff remains positive for profit shifting reasons and is inversely related to the ratio between size of the economy and fixed entry cost $S / F$. When available, the optimal subsidy must maximize the sum of domestic profits and revenues.

As a second application, let us think of an integrated market of size $\bar{S}=$ $S+S^{*}$ where the domestic firm is competing with international firms, and the domestic government can choose the subsidy $\tau$ while the international firms face an exogenous and common policy normalized at $t=0$. The equilibrium must satisfy the same conditions as above, therefore the domestic subsidy does not affect the strategies of the international firms and consumer surplus, in line with our Theorem above. However, the subsidy reduces the number of firms $n(\tau)$ and affects the strategy of the domestic firm $x(\tau)$. If the subsidy is a pure transfer of domestic resources, welfare can be written as:

$$
W(\tau)=S u\left[\beta^{*}+h\left(x^{*}\right)\right]+\bar{S} \Pi\left[x(\tau),(n(\tau)-1) h\left(x^{*}\right), 0\right]-F
$$

where the entire first term is independent from the domestic policy and the second term takes in consideration that the subsidy is a pure transfer or resources (affects profits indirectly but not directly). As usual, the optimal subsidy maximizes welfare taking into account the impact on the production or pricing strategies of the rivals. In traditional models with exogenous entry in a third country, this leads to a negative subsidy (an export tax) under price competition (Eaton and Grossman, 1986) and to a positive subsidy only under strategic substitutability (Brander and Spencer, 1985); when one considers an integrated market including domestic consumers, the impact of the policy on domestic consumer surplus tends to reduce the optimal tax or to increase the optimal subsidy. In the case of endogenous entry, however, the production subsidy does not affect the production or pricing strategies of the competitors, but only reduces their number, and, according to our Theorem above, does not affect consumer surplus at home and abroad. Therefore, the optimal policy must take into account only the impact on foreign entry in the integrated market and its feedback on the domestic profits. As we will see in Section 4, and contrary to the traditional literature, this implies that it is always optimal to set a positive subsidy to domestic production, independent from the form of competition and from the relative size of the domestic market.

This same structure can be used to analyze a number of other issues in international trade theory and policy. One is the role of a multinational with cost advantages in a local market: according to our first Theorem, its entry does not affect the strategies of the local firms but only their number, shifting profits to the multinationals. Other applications concern the optimality of different forms of indirect promotion of the domestic production, which can turn domestic 
firms into aggressive competitors abroad, or the analysis of lobbying on trade policy. These applications will be examined in Section 5.

\section{Competition effect and welfare: examples}

In this section we discuss two classic applications of the general framework with EMS, based on a model with homogenous goods and linear demand $a$ la Brander (1981) and on the classic Krugman (1980) model extended to take into account different forms of strategic interactions between the firms. In both cases we examine the impact of opening up to trade on competition and on welfare.

\subsection{The case of linear demand}

Let us start our examination of EMS from the only example which has been examined in the trade literature, the one of homogenous goods (Brander and Krugman, 1983). Consider an autarchic economy characterized by a market with $S$ consumers with utility:

$$
u=a C-\frac{C^{2}}{2}-Y
$$

with $C$ consumption of a good produced by $n$ imperfectly competitive firms and $Y$ is the numeraire which is produced under perfect competition. The demand of the first good is $D=a-p$ where $p$ is the equilibrium price. Total production $X=S(a-p)$ can be inverted to derive the inverse demand $p=a-X / S$. The profit function of each firm is:

$$
\pi_{i}=(a-X / S) x_{i}-c x_{i}-F
$$

where $x_{i}$ is its production and $c$ is the constant marginal cost. This profit function is clearly nested in our general model. In Cournot equilibrium each firm produces $x=(a-c) S /(n+1)$. When entry is endogenous the number of firms is:

$$
n=(a-c) \sqrt{\frac{S}{F}}-1
$$

with individual production $x=\sqrt{S F}$ and price:

$$
p=c+\sqrt{\frac{F}{S}}
$$

Notice that welfare is $U=S u=X^{2} / 2 S$, which is clearly increasing in the total production and therefore decreasing in the equilibrium price. 
Consider opening up to trade with an other country characterized by identical agents and total population $S^{*}$, with $\bar{S}=S+S^{*}$ defined as the size of the integrated market. It is immediate to derive that the new equilibrium price is $p=c+\sqrt{F / \bar{S}}$ which is reduced because of stronger competition in the integrated market. However, the total number of firms becomes $n+n^{*}=(a-c) \sqrt{S / F}-2$, which is lower than the number of firms active in autarchy, $(a-c)\left(\sqrt{S / F}+\sqrt{S^{*} / F}\right)-2$. Trade has increased concentration in the integrated market: this represents an example of beneficial concentration, because production becomes more efficient thanks to the reduction of spending in fixed costs. Consequently trade increases welfare (as in Brander and Krugman, 1981).

However, the equilibrium characterized above is inefficient, typically generating excessive mark ups and excessive business creation (Mankiw and Whinston, 1986): trivially, the first best would require a single firm selling at the average cost, but a second best taking strategic interactions into account would also require a smaller number of firms compared to (10). This inefficiency is the reason for which the EMS approach gives rise to new implications for the impact of structural and policy shocks and to a new role for trade policy.

\subsection{The case of CES preferences}

Let us move to the model with isoelastic preferences introduced by Dixit and Stiglitz (1977) and applied to trade theory by Krugman (1980). Consider a market with $S$ agents with utility:

$$
u=\left[\sum_{j=1}^{n} C(j)^{\frac{\theta-1}{\theta}}\right]^{\frac{\theta}{\theta-1}}
$$

where $n$ is the number of goods and $\theta>1$ is the elasticity of substitution. Each consumer maximizes utility under the budget constraint $\sum_{j=1}^{n} p(j) C(j)=1$, where we normalize the wage and labor supply to unity. Each good $i$ is produced according to the linear production function $x(i)=l(i)$, where $l(i)$ is the labor input used by firm $i$, with $\sum_{j=1}^{n} l(j)=S$. Therefore, total sales correspond to the size of the market $S$. Defining total demand of each good as $x(i)=C(i) S$, the profit function of each firm can be expressed in terms of production or prices:

$$
\pi_{i}=\frac{x(i)^{\frac{\theta-1}{\theta}} S}{\sum_{j=1}^{n} x(j)^{\frac{\theta-1}{\theta}}}-x(i)-F=\frac{[p(i)-1] p(i)^{-\theta} S}{\sum_{j=1}^{n} p(j)^{-(\theta-1)}}-F
$$


In both cases, the profit function is nested in our general model and is associated with a consumer surplus depending on the relevant aggregate statistics. ${ }^{6}$ Competition in quantities or prices between firms determines the market structure. In a symmetric equilibrium, each one of the $n$ goods is produced in quantity $x$, so that the utility of each agent is $u=(x / S) n^{\frac{\theta}{\theta-1}}$, which increases in the number of goods and in the consumption of the agent.

The Krugman (1980) model and most of the subsequent literature ignore the strategic interactions between firms, assuming monopolistic behavior. The optimal price corresponds to a constant mark up on the unitary marginal cost $p^{M}=\theta /(\theta-1)$. Imposing the endogenous entry condition $\left(p^{M}-1\right) x=F$ for each firm, we have the equilibrium production of each good $x=F(\theta-1)$. The number of firms can be derived from the resource constraint equating the value of total sales and labor income $n p^{M} x=S$, or from the market clearing condition for the labor market equating labor supply and labor demand, $S=n(F+x)$. Accordingly, the endogenous number of firms is:

$$
n=\frac{S}{\theta F}
$$

Mark ups and production per firm are independent from the size of the economy $S$, while the number of firms is directly proportional to it, a result that does not find empirical support, as we will suggest in the Appendix.

The fundamental contribution of the Krugman model is in the analysis of market integration with other countries, which leads to intra-industry trade of the differentiated goods produced by each country, and to gains for the consumers associated with an increase in the number of varieties available. For instance, consider opening up to trade with a country with $S^{*}$ identical agents. The proportional increase in total demand generates an equilibrium number of varieties $n+n^{*}=\bar{S} / \theta$ where $\bar{S}$ is the population of the integrated market. The price and the production of each firm remain the same as in the closed economy; since $C(i)=x / \bar{S}$ consumers reduce their consumption for each single variety.

\subsubsection{Competition in quantities}

Let us consider competition in quantities in the Krugman (1980) model. The Cournot equilibrium is characterized by a price $p=\theta n /(\theta-1)(n-1)$, which is clearly decreasing in the number of firms (and converging to the traditional one only with infinite firms).

For the sake of simplicity, we start our investigation in the extreme case of homogenous goods $(\theta \rightarrow \infty)$, in which the possibility of gains from variety

\footnotetext{
${ }^{6}$ Notice that consumer surplus depends on the aggregate statistics $\sum_{j=1}^{n} h(x(j))$ with $h(x)=x^{1-1 / \theta}$. The profit functions depend on the same aggregate statistics.
} 
is absent. Consider first the equilibrium of a closed economy. Endogenous entry and market clearing conditions lead to the following price for each variety $p=\sqrt{S} /(\sqrt{S}-\sqrt{F})$ and to the production level $x=\sqrt{F}(\sqrt{S}-\sqrt{F})$. Contrary to what happens in the monopolistic framework, where price and production per firm are independent from the domestic labor force, now the price is decreasing in the labor force and the production of each firm is increasing in it to cover the fixed costs of entry. This result is due to a competition effect associated with the positive impact of the size of the market on the equilibrium number of firms, which is now:

$$
n=\sqrt{\frac{S}{F}}
$$

Notice that the number of firms is increasing and concave in the size of the economy, exactly as in the linear model - see(10). Finally, notice that consumption per variety here becomes $C(i)=\sqrt{F}(\sqrt{S}-\sqrt{F}) / S$.

Consider opening up to trade with an other country characterized by identical agents so that the population of the integrated market is $\bar{S}$. It is immediate to derive that the new equilibrium implies the price $p=1 /(1-\sqrt{F / \bar{S}})$. The total number of firms becomes $n+n^{*}=\sqrt{S / F}$, which is lower than the number of firms active in autarchy, $\sqrt{S / F}+\sqrt{S^{*} / F}$. Nevertheless, the strengthening of competition in the integrated market leads to a lower international price level, and to the larger production for each firm. Trade has reduced the total number of firms, inducing an increase in world market concentration: in our case of homogenous goods, this represents an example of beneficial concentration, because production becames more efficient thanks to the reduction of the spending in fixed costs. ${ }^{7}$

Of course, in case of imperfect substitutability between goods, product variety is beneficial and the impact of trade is more complex, but the competition effect of trade on prices and the reduction in the equilibrium number of varieties produced in each country persist. In particular, one can verify that a

\footnotetext{
${ }^{7}$ To clarify the implications of the EMSs approach for trade, let us consider the example of two identical countries opening up to trade. Suppose that ten firms producing an homogenous good are active in each country under autarchy. After the two countries open up to trade with each other, the EMSs approach implies that only fourteen firms, seven in each country, remain active. This implies that trade leads to the foreclosure of three firms in each country, which is the consequence of a reduction of the mark up by about 30\%. Formally, if $n=\sqrt{S / F}=10$, we must have $n+n^{*}=n \sqrt{2} \simeq 14$. Moreover, if the autarchic price was $1 /(1-1 / 10)$, the new one must be $1 /(1-1 / 14)$, which is equivalent to a reduction of the mark up from $11.1 \%$ to $7.7 \%$. This is a $30 \%$ reduction. Nevertheless, it is clear that trade increases utility because the price of the homogenous good is reduced everywhere (and there is a more limited waste of labor resources in fixed costs).
} 
closed economy is characterized by EMSs with the following price and number of firms:

$$
\begin{gathered}
p=\frac{\theta}{(\theta-1)}\left(1-\frac{2 \theta F}{S+\sqrt{S^{2}+4 \theta(\theta-1) F S}}\right)^{-1} \\
n=\frac{S}{2 \theta F}+\sqrt{\left(\frac{S}{2 \theta F}\right)^{2}+\frac{(\theta-1) S}{\theta F}}
\end{gathered}
$$

and an increase in the size of the economy leads to a reduction of the former and to a less than proportional increase of the latter. This Cournot equilibrium with endogenous entry is inefficient compared to the Krugman equilibrium characterized above because it generates higher mark ups and attracts an excessive number of firms (Mankiw and Whinston, 1986). As before, we can verify the impact of opening up to trade. The equilibrium mark up decreases, which leads to business destruction at the local level and to a larger production by each surviving firm. The price reduction/business destruction effect is reduced when the degree of substitutability $\theta$ decreases.

Recent industrial organization research on markets with EMSs provides evidence on the competition effect outlined above (Bresnahan and Reiss, 1987, Manuszak, 2002, and Campbell and Hopenhayn, 2005). Some novel empirical evidence in support of the less than proportional relation between market size and number of firms is provided in the Appendix, which provides an econometric test of the structural relation (14) derived from the Krugman model and of the alternative relations (15) or (17) derived from the EMS approach. Looking at panel data from different industries in the German manufacturing sector, we show that a support of the EMS approach emerges quite clearly: estimating a structural relation as $\ln n=\beta_{0}+\beta_{1} \ln S+\varepsilon$, the coefficient $\beta_{1}$ appears significantly lower than one and close to 0.5 (as predicted by the Cournot model with homogenous goods).

\subsubsection{Competition in prices}

To conclude our extension of the Krugman model to strategic interactions, let us consider competition in prices. The Bertrand equilibrium price is $p=$ $[\theta(n-1)+1] /(\theta-1)(n-1)$. Under endogenous entry of firms, the autarchic price becomes:

$$
p=\frac{\theta S}{(\theta-1)(S-F)}
$$


which corresponds to the following number of goods/firms:

$$
n=\frac{S}{\theta F}+\frac{\theta-1}{\theta}
$$

The equilibrium production level is $x=F(\theta-1)(S-F) /[S+(\theta-1) F]$ : in a larger economy there are more firms and the strengthening of competition between them reduces the mark ups and increases the production of each firm. Also in this case, the equilibrium is inefficient, because of an excessive mark up ue to the strategic interactions.

Consider now the opening up of this economy to trade. The new equilibrium is characterized by the price $p=\theta /(\theta-1)(1-F / \bar{S})$, the total number of varieties produced becomes $n+n^{*}=\bar{S} / \theta F+1-1 / \theta$ and the individual production levels are increased accordingly. In this case, opening up to trade leads to a lower international price level without reducing the number of varieties produced in each country (or reducing it by at most one unit if we take in consideration the integer constraint on the number of firms), and increasing the production of each one. However, once again the beneficial impact of trade emerges from both a price reduction and an increase of the number of available varieties.

\subsubsection{Welfare implications}

The introduction of strategic interactions in the Krugman model has shown that globalization can affect the market structures in pervasive ways and induce new sources of gains from trade. Summing up:

Proposition 1. Under endogenous market structures in the Krugman model, opening up to trade decreases the price level, increases the production of each firm and (weakly) decreases the number of firms in each country, so that the total number of consumed varieties increases (less than) proportionally, with a beneficial impact on consumer welfare.

The relevance of the mechanism associated with the strategic interactions depends on the type of traded goods under consideration. At one extreme we have perfectly differentiated goods with competition in prices: for these goods, all the gains from opening up to trade derive from an increase in the number of consumed varieties and not from price changes, while business destruction is absent. At the other extreme we have homogenous goods with competition in quantities: for these, all the gains from trade derive from lower prices, but business destruction is heavy. More importantly, the equilibria characterized 
above are inefficient because of imperfect competition, which generates excessive mark ups and excessive business creation (Mankiw and Whinston, 1986). For this reason, the EMS approach gives raise to new opportuinities for policy and generates new implications for the optimal trade policy. To these implications we turn in the next sections.

\section{$3 \quad$ Import tariffs for domestic markets}

In the theory of trade policy under imperfect competition, endogenous entry has been considered only to study special cases and, in particular, the case of monopolistic behavior in a model with two countries: in this setup Helpman and Krugman (1989) have confirmed the traditional optimality of a positive tariff for a large country with the purpose of improving the terms of trade. However, most of the investigations are focused on models with an exogenous number of domestic and foreign firms and on the incentives to adopt tariffs for profit shifting reasons (see Helpman and Krugman, 1989, and Bhattacharjea, 1995). In this section we extend these investigations to the case of EMSs to characterize the optimal import tariff. For the sake of simplicity we develop most of the analysis focusing on homogenous goods and competition in quantities. This allows us to derive a new formula for the optimal import tariff that is inversely related to the ratio between the entry costs and the size of the market. Later on we will discuss how the results can be extended to the case of CES preferences and to the more general framework.

\subsection{The case of linear demand}

Let us consider the same linear model of competition in quantities of the previous section, with $n$ firms active in the domestic market: a domestic firm and $n-1$ foreign firms. The government chooses a specific tariff $t$ on the imports of all the foreign firms and possibly also a specific production subsidy $\tau$ on the sales of a single national firm. With $S$ domestic consumers, the inverse demand is $p=a-X / S$ where $a$ represents the maximum willingness to pay. The marginal cost of production is $c$ and the fixed cost is $F$. The profit function of the domestic firm is:

$$
\pi=(a-X / S+\tau) x-c x-F
$$

where $x$ is its own production. The profit function of a foreign firm $i$ is:

$$
\pi_{i}^{*}=(a-X / S-t) x_{i}^{*}-c x_{i}^{*}-F
$$


where $x_{i}^{*}$ is its production. In Cournot equilibrium the production levels are respectively:

$$
x(\tau, t)=\frac{a-c+(n-1) t+n \tau}{1+n} S \quad \text { and } \quad x^{*}(\tau, t)=\frac{a-c-2 t-\tau}{1+n} S
$$

which generate profits $\pi=x(\tau, t)^{2} / S-F$ for the domestic firm, and:

$$
\pi^{*}=\frac{x^{*}(\tau, t)^{2}}{S}-F
$$

for the international firms. With an exogenous number of firms, the profit maximizing tariff (when $\tau=0)^{8}$ can be derived as $t_{H}=3(a-c) /(7+n)$. The role of this tariff is to reduce foreign production while shifting profits toward the domestic firm and collecting some revenue, whose marginal benefits are balanced against the social marginal cost of the price increase. Notice that the optimal tariff does not depend on the size of the domestic market and of course not even on the entry costs, but it increases with the size parameter $a$ which measures the maximum willingness to pay for the good and decreases with the marginal cost of production $c$.

Now, imagine that entry of foreign firms in the domestic market is endogenous. As long as there are foreign firms in the market and $t+\tau>0$, the zero profit condition must be binding on them, which implies:

$$
n=(a-c-2 t-\tau) \sqrt{\frac{S}{F}}-1
$$

with a production of the foreign firms $x^{*}=\sqrt{S F}$, which is independent from the policy tools in line with our first Theorem. The production of the domestic firm is:

$$
x=\sqrt{S F}+(\tau+t) S
$$

therefore total production can be derived as:

$$
X=(a-c-t) S-\sqrt{S F}
$$

Such an equilibrium is consistent with $n \geq 2$ for $t \leq(a-c-\tau-3 \sqrt{F / S}) / 2$.

\footnotetext{
${ }^{8}$ If both instruments are available, welfare is maximized by $\tilde{t}=0$ and $\tilde{s}=a-c$, that is by setting the price equal to the marginal cost and driving out of the market all foreign firms. See Bhattacharjea (1995) for further details.
} 
If this is the case, welfare becomes:

$$
\begin{aligned}
W(\tau, t)= & \underbrace{\frac{((a-c-t) S-\sqrt{S F})^{2}}{2 S}}_{\text {Consumer surplus }}+\underbrace{\frac{(\sqrt{S F}+(\tau+t) S)^{2}}{S}-F}_{\text {Domestic profits }}+ \\
& \underbrace{+t[(a-c-2 t-\tau) S-2 \sqrt{S F}]}_{\text {Tariff revenue }}-\underbrace{\tau[\sqrt{S F}+(\tau+t) S]}_{\text {Subsidy cost }}
\end{aligned}
$$

where the subsidy does not affect consumer surplus, in line with our first Theorem, but the import tariffs affect all the components of welfare. For any given small subsidy, and in particular in the case of no subsidy (when $\tau=0$ ), the optimal unilateral tariff can be derived as:

$$
t_{H}=\sqrt{\frac{F}{S}}
$$

which is consistent with entry of some foreign firms as long as the fixed cost is small enough (otherwise, it is optimal to set the prohibitive tariff). The optimal tariff does not depend anymore on the size parameter measuring the maximum willingness to pay of the consumers and on the marginal cost of production. Instead, it depends positively on the fixed cost $F$ and negatively on the size of the domestic market $S$. Contrary to what happens in the model with exogenous entry, the tariff does not affect the production of the foreign firms, which remains the same. The main role of the tariff is to reduce entry of these firms, which reduces the production inefficiency associated with the free trade equilibrium due to the excessive price and entry à la Mankiw and Whinston (1986) examined in the previous section. This creates space for increasing the market share and the profits of the domestic firm (compared to the zero profits of case with free trade), while collecting also some tariff revenue. These benefits are larger when the fixed cost is high relative to the size of the market because in this case the production inefficiency associated with free trade is high. In the limit case of perfect competition (zero fixed costs) we obtain the traditional result for which free trade is optimal.

Finally, notice that welfare turns out to be a linearly increasing function of the subsidy: therefore, if both the instruments are available, the first best can be obtained by setting $\tilde{t}=0$ and $\hat{\tau}=a-c$.

The equilibrium production of the domestic firm is $x=2 \sqrt{S F}$, which is twice as the production of the other firms, and the domestic profits are $\pi=3 F$. Total imports are $I M P=(a-c) S-4 \sqrt{S F}$, which delivers a tariff revenue $R\left(t(n-1) h\left(x^{*}\right)\right)=(a-c) \sqrt{S F}-4 F$. 
It is important to remark that the same outcome could be obtained imposing a quota $Q=I M P$ and auctioning the rights to sell at a price $t_{H}$ : endogenous entry of foreign producers would deliver the same allocation of production as above. $^{9}$

While the domestic economy gains from the positive profits of the domestic firm and from the revenue collected from the foreign firms, its consumers have to face a higher equilibrium price:

$$
p=c+2 \sqrt{\frac{F}{S}}
$$

compared to the one emerging under free trade, given by (11). Of course, the reduction in consumer surplus is more than compensated by the gains in domestic profits and tariff revenues.

When the size of the market becomes large, the optimal tariff tends to zero, a result that is consistent with the traditional idea that a free trade policy is optimal when the domestic firms (her only one) are too small to affect the terms of trade. In general, we can state the following principle:

PROPOSITION 2. Under endogenous market structures in the domestic market, the optimal trade policy implies a positive import tariff (inversely related to the ratio between size of the economy and fixed entry cost) or a binding quota on imports so as to generate positive profits for the domestic firm.

\subsection{The case of CES preferences}

The nature of the optimal trade policy extends to the case of imperfect substitutability between products and competition in quantities, for instance with inverse demand functions derived from CES preferences. In such a case it would remain optimal to adopt a positive import tariff to generate profits for the domestic firm and tariff revenues from the foreign firms. Moreover, as long as product differentiation and the taste for variety are strong enough, it would be always optimal, even when subsidies to domestic production are available, to allow for some entry of foreign varieties.

In a model of competition in prices with product differentiation, as that derived from the CES preferences, it is also possible to show that domestic welfare is maximized when the import tariff and the subsidy maximize the sum of tariff revenue and the profits of the national firm net of its subsidies, taking

\footnotetext{
${ }^{9} \mathrm{~A}$ smaller quota would ask a higher bidding price for the rights to sell, and would deliver a different equilibrium: the domestic firm would also reduce its production. However, it is immediate to verify that the optimal quota reproduces the equilibrium with the optimal tariff.
} 
into account that the number of foreign firms is endogenous and negatively related to the tariff. Despite a closed form solution is not available, in this case it is still optimal to choose a non-prohibitive tariff on imports and (possibly) a positive subsidy to domestic production.

It is important to remind the reader that we are referring to optimal unilateral policies. As well known, also in this contest retaliation by foreign countries by imposing similar import tariffs may lead to an inefficient Nash equilibrium trade policy. Moreover, keeping as neutral the policies of the foreign countries for their exporting firms has implied a substantial loss of generality: these countries may have strong incentives to support their firms with consequences for the domestic market as well. We now turn to the complementary issue of the optimal policies that promote exports, which will deliver new policy recommendations compared to the traditional outcomes.

\section{Production subsidies for integrated markets}

The neoclassical theory based on perfect competition associates the scope of trade policy with improvements in the terms of trade (Lerner, 1934): as long as a country is large enough to affect it, the optimal unilateral policy is to set a tax on exportable domestic production. The new trade theory associates the scope of strategic trade policy with profit shifting. Eaton and Grossman (1986) have shown that the optimal unilateral policy is a tax on exportable domestic production under price competition. Under quantity competition, a subsidy to domestic production can be optimal only under certain conditions (Brander and Spencer, 1985; Dixit, 1984). Moreover, when part of the production is sold in the home country, ${ }^{10}$ the optimal policy must take in consideration also the impact on the domestic consumer surplus: typically, this tends to bias the optimal policy toward lower taxes or higher subsidies to reduce the prices, and such a bias is stronger when the size of the domestic country is large relative to the rest of the integrated market.

In this section we analyze the optimal unilateral policy for a market where a domestic firm and international firms compete to serve integrated domestic and international markets. We focus on the case of endogenous entry of international firms and we characterize the optimal policy under quite general conditions: this turns out to be a positive subsidy to the entire domestic production independently from the form of competition and from the relative size of the domestic country. We will now verify these results in a few examples.

\footnotetext{
${ }^{10}$ Our analysis applies when export subsidies are forebidden, but subsidies to the entire domestic production are possible. This is exactly what happens under the WTO rule.
} 


\subsection{Competition in quantities}

Consider a general model of competition in quantities with a specific subsidy. Assuming a general inverse demand function and a general cost function, the profit function of firm $i$ facing a specific subsidy $\tau_{i}$ is:

$$
\pi_{i}=x(i)\left[p\left(x(i), \beta_{i}\right)+\tau_{i}\right]-c(x(i))-F
$$

where $x(i)$ is its production and $\beta_{i}=\sum_{j \neq i} h(x(j))$, while $c(x)$ is a positive and increasing cost function. Let us focus on the case of a subsidy $\tau$ for the domestic firm and no subsidy for the other firms. The equilibrium conditions in the competition stage are:

$$
p\left(x^{*}, \beta^{*}\right)+x^{*} p_{1}\left(x^{*}, \beta^{*}\right)=c^{\prime}\left(x^{*}\right), \quad \tau+p(x, \beta)+x p_{1}(x, \beta)=c^{\prime}(x)
$$

where $\beta^{*}=(n-2) h\left(x^{*}\right)+h(x)$ is the spillover received by an international firm from the strategies of all the other firms in the market and $\beta=(n-1) h\left(x^{*}\right)$ is the spillover for the domestic firm.

With a given number of firms the two conditions above define $x^{*}(\tau)$ and $x(\tau)$. Comparative statics analysis shows that $x^{* \prime}(\tau)<0$ as long as strategic substitutability holds, and $x^{\prime}(\tau)<0$ always. The welfare function of the home country can be expressed as the domestic consumer surplus, which depends on both the equilibrium strategies, plus the domestic profits net of the subsidy costs. The optimal subsidy increases in the size of the total consumer surplus and therefore in the relative size of the domestic economy. ${ }^{11}$

\footnotetext{
${ }^{11}$ As an example, consider the case of homogenous goods and linear demand $p=a-X / \bar{S}$ and cost. The number of domestic consumers is $S=\vartheta \bar{S}$ where $\vartheta \in[0,1]$ represents the relative size of the domestic country. The Cournot equilibrium is given by:

$$
x(\tau)=\frac{a-c+n \tau}{1+n} \bar{S} \quad \text { and } \quad x^{*}(\tau)=\frac{a-c-\tau}{1+n} \bar{S}
$$

Domestic profits are $\pi=x(\tau)^{2} / \bar{S}-F$ for the domestic firm and the cost of the subsidy is $\tau x(\tau)$, while the domestic consumer surplus is given by $U=(S / 2)[X / \bar{S}]^{2}$. Accordingly, total welfare is:

$$
W(\tau)=\frac{X^{2} \vartheta}{2 \bar{S}}+\frac{x(\tau)^{2}}{\bar{S}}-F-\tau x(\tau)
$$

whose maximization provides the optimal trade policy:

$$
\tau(n)=\frac{[n(1+\vartheta)-1](a-c)}{2 n-\vartheta}>0
$$

When $\vartheta=1$ we are back in the case of a closed economy in which it is optimal to implement the first best production with the domestic firm. When $\vartheta=0$ we are in the case of a third market analyzed by Brander and Spencer (1985) and the optimal subsidy becomes $\tau(n)=(n-1)(a-c) / 2 n$. More generally, the optimal subsidy increases with the size of the economy because the profit shifting motive for subsidizing exports becomes less relevant and
} 
When entry is endogenous, the productive stage is characterized not only by the optimality conditions for the domestic firm and for the representative foreign firm, but also by the free entry condition:

$$
x^{*} p\left(x^{*}, \beta^{*}\right)-c\left(x^{*}\right)=F
$$

The equilibrium system defines the output of each firm and the number of firms as functions of the subsidy $\tau$. We know from Proposition 3 that the production of the foreign firms $x^{*}$ and their spillovers $\beta^{*}$ do not depend on the subsidy, while $x(\tau)$ and $\beta(\tau)$ depend on it. Moreover, the domestic consumer surplus $U=S u\left[\beta^{*}+h\left(x^{*}\right)\right]$ is independent from the subsidy. Therefore, we can write the domestic welfare as:

$$
W(\tau)=\underbrace{S u\left[\beta^{*}+h\left(x^{*}\right)\right]}_{\text {Consumer surplus }}+\underbrace{x(\tau)[p(x(\tau), \beta(\tau))+\tau]-c(x)-F}_{\text {Domestic profits }}-\underbrace{\tau x(\tau)}_{\text {Subsidy cos }}(30)
$$

where the first term is policy-independent. Welfare maximization entails an interior solution for the optimal subsidy if goods are poor substitutes or if marginal costs are increasing enough (if this is not the case, a prohibitive subsidy is optimal). Deriving the welfare maximizing production subsidy (and using the first order condition for the domestic firm) we obtain:

$$
\tau_{H}=-p_{2}(x, \beta) h^{\prime}(x) x
$$

Notice that the optimal production subsidy is always positive and does not depend on the relative size of the domestic country: it is the same whether the firm is exporting its entire production or only a part of it. ${ }^{12}$ Nevertheless, the optimal policy can depend on the size of the global market, as we will verify in the examples below. Summarizing, we have:

Proposition 3. Under endogenous entry in the integrated market with competition in quantities, the optimal subsidy to domestic production is always positive and independent from the relative size of the domestic market.

In general, the upper bound for the optimal subsidy emerges in the case of homogenous goods, which is consistent with a non-prohibitive subsidy if the marginal costs are increasing enough. Defining the elasticity of demand as $\varepsilon \equiv-p / x p^{\prime}$, the optimal subsidy simplifies to $\tau_{H}=p / \varepsilon$. Therefore, under

the purpose of reducing domestic prices becomes more important. Notice that, for a given size of the economy, the optimal subsidy is increasing in the number of international firms.

${ }^{12}$ However, notice that when the size of the country is large, as we have seen in the previous section, there is an incentive to adopt an import tariff on foreign production. 
perfect substitutability, the optimal subsidy as a percentage of the price of the domestic firm is equal to the inverse of the elasticity of the international demand to the price: the more elastic is demand the smaller is the optimal subsidy, and this tends to zero when demand becomes infinitely elastic.

\subsubsection{The case of linear demand}

As a further example of the homogenous goods case, consider the a linear demand function $p=a-X / \bar{S}$ together with a quadratic cost function $c(x)=$ $x^{2} / 2{ }^{13}$ Looking at the Cournot equilibrium between $n$ firms for a given subsidy $\tau$ of the domestic firm, and imposing the free entry condition, we obtain the equilibrium production for each international firm:

$$
x^{*}=\sqrt{\frac{2 \bar{S} F}{2+\bar{S}}}
$$

and the number of firms:

$$
n=\left(a-\frac{\tau}{1+\bar{S}}\right) \sqrt{\frac{(2+\bar{S}) \bar{S}}{2 F}}-1-\bar{S}
$$

which imply total production $X=a \bar{S}-(1+\bar{S}) x^{*}$ and a price $p=(1+$ $\bar{S}) \sqrt{2 F /(2+\bar{S}) \bar{S}}$. The equilibrium production of the subsidized firm is:

$$
x(\tau)=x^{*}+\frac{\tau \bar{S}}{1+\bar{S}}
$$

Consistently with Proposition 3, the subsidy does not affect the individual production of the other firms, but decreases their number. Moreover, consumer surplus is now a function of the total production, which does not depend on policy, $u=(X / \bar{S})^{2} / 2$. Domestic profits are:

$$
\pi_{H}=\frac{2+\bar{S}}{2 \bar{S}}\left(x^{*}+\frac{\tau \bar{S}}{1+\bar{S}}\right)^{2}-F
$$

The government maximizes profits net of the tax revenue necessary to finance the subsidies:

$$
W(\tau)=\frac{1}{2}\left(\frac{X}{\bar{S}}\right)^{2} S+x(\tau)(1+\bar{S}) \sqrt{\frac{2 F}{(2+\bar{S}) \bar{S}}}-\frac{x(\tau)^{2}}{2}-F
$$

\footnotetext{
${ }^{13}$ We focus on in creasing marginal costs becuase in case of a constant marginal cost we would obtain the optimality of a prohibitive subsidy.
} 
where the first term is independent from the subsidy. Welfare is maximized when:

$$
x(\tau)=(1+\bar{S}) \sqrt{\frac{2 F}{(2+\bar{S}) \bar{S}}}
$$

which requires the following optimal subsidy:

$$
\tau_{H}=\left(1+\frac{1}{\bar{S}}\right) \sqrt{\frac{2 F}{(2+\bar{S}) \bar{S}}}>0
$$

This is approaching zero when the size of the market increases indefinitely. Notice also that when the fixed cost of entry decreases, the level of concentration in the market is reduced and the optimal subsidy goes down: in the limit case of perfect competition (zero fixed costs) we obtain the traditional result for which free trade is optimal.

\subsubsection{The case of CES preferences}

Let us consider the usual isoelastic preferences (12), which lead to the inverse demand:

$$
p(x, \beta)=\frac{x^{-1 / \theta} \bar{S}}{x^{1-1 / \theta}+\beta}
$$

with $h(x)=x^{1-1 / \theta}$. Applying directly the formula for the optimal production subsity (31) we obtain:

$$
\tau_{H}=\frac{(\theta-1) p^{2} x}{\theta \bar{S}}
$$

which leads the domestic firm to sell its good at a price $p=c \theta /(\theta-1)$ lower than the other firms. This allows us to rewrite the optimal export subsidy as:

$$
\tau_{H}=\frac{p}{(\bar{S} / c x)}
$$

which is decreasing in the size of the international market $\bar{S}$. In other words, large countries exporting in small markets (with small $\bar{S}$ ) should adopt large subsidies for their exporting firms, while small open economies (exporting to large markets) should tend to commit to free trade.

\subsection{Competition in prices}

Consider a general model of price competition with a specific subsidy $\tau_{i}$ for firm $i$, such that its profits are given by:

$$
\pi_{i}=\left(p_{i}-c+\tau_{i}\right) D\left(p_{i}, \beta_{i}\right)-F
$$


where $c$ is the constant marginal cost and the demand function is decreasing in both arguments with $\beta_{i}=\sum_{j \neq i} g\left(p_{j}\right)$ for positive and decreasing functions $g(p)$ : this implies that the demand for the domestic good is decreasing in its price and increasing in all the other prices. Notice that by setting $x=1 / p$ and $h(x)=g(1 / x)$, the profit function is nested in our general framework. Substitutability between goods is guaranteed by the fact that the cross derivative $\partial D_{i} / \partial p_{j} \equiv \Delta_{i j}$ is always positive: $\Delta_{i j}=D_{2} g^{\prime}\left(p_{j}\right)>0$ for any $i$ and $j$. The gross profits of the domestic firm are:

$$
\Pi=(p-c+\tau) D(p, \beta)
$$

The first order equilibrium conditions in the competition stage for the foreign and domestic firms are:

$$
\left(p^{*}-c\right) D_{1}\left(p^{*}, \beta\right)+D\left(p^{*}, \beta\right)=0, \quad(p-c+\tau) D_{1}(p, \beta)+D(p, \beta)=0
$$

where $\beta^{*}=(n-2) g\left(p^{*}\right)+g(p)$ is the spillover received by an international firm from the strategies of all the other firms in the market and $\beta=(n-1) g\left(p^{*}\right)$ is the spillover for the domestic firm. This system provides the prices and the number of firms as functions of the subsidy $\tau$ and the number of firms $n$, with $p^{\prime}(\tau)<0$ and $p^{* \prime}(\tau)<0$. This implies that, in case of exogenous entry in a third market, the optimal policy under price competition requires a tax on domestic production, as first suggested by Eaton and Grossman (1986). However, taking into account the negative impact of the tax on domestic consumer surplus can reduce the optimal tax or turn it into a production subsidy if the relative size of the domestic economy is large.

When entry is endogenous, beyond the first order conditions above, we need to take into account the free entry condition:

$$
\left(p^{*}-c\right) D\left(p^{*}, \beta^{*}\right)=F
$$

Our first Theorem tells us that the price of the foreign firms $p^{*}$ and their spillover $\beta^{*}$ do not change with the subsidy, while the price of the domestic firm $p(\tau)$ and its spillover $\beta(\tau)$ depend on the subsidy. Moreover, since consumer surplus depends on the aggregate statistics $\sum_{j=1}^{n} g\left(p_{j}\right)$, in equilibrium we have:

$$
u\left[\sum_{j=1}^{n} g\left(p_{j}\right)\right]=u\left[\beta^{*}+g\left(p^{*}\right)\right]
$$

which is independent from the subsidy. Therefore, we can write total welfare of 
the domestic country as:

$$
W(\tau)=\underbrace{S u\left[\beta^{*}+g\left(p^{*}\right)\right]}_{\text {Consumer surplus }}+\underbrace{[p(\tau)-c+\tau] D[p(\tau), \beta(\tau)]-F}_{\text {Net domestic profits }}-\underbrace{\tau D[1}_{\text {Subsidy cost }}(41)
$$

where the first term is policy-independent. Let us define $\Delta(p, \beta)=D_{2}(p, \beta) g^{\prime}(p)$ as the indirect effect that a price change exerts on demand through the change in the endogenous number of firms. Deriving the welfare function with respect to the production subsidy and using the equilibrium first order condition for the domestic firm, we obtain the following implicit expression:

$$
\tau_{H}=\frac{(p-c) \Delta(p, \beta)}{\left|D_{1}(p, \beta)\right|}
$$

The optimal subsidy to domestic production is always positive and depends on the impact of a price change on the entry of competitors $(\Delta(p, \beta))$ : the stronger is this effect (for instance because goods are close substitutes), the larger should be the optimal subsidy. Moreover, the optimal susbidy does not depend on the relative size of the domestic economy. It is the same whether the domestic country exports its entire production or only part of it. The reason is that profits are gained worldwide, while the consumer surplus is not affected by the subsidy. Summarizing, we have:

Proposition 4. Under endogenous entry in the integrated market with competition in prices, the optimal subsidy to domestic production is always positive and independent from the relative size of the domestic market.

We can also notice that the optimal subsidy as a percentage of the price of the domestic firm must be smaller than the inverse of the demand elasticity, which was the optimal subsidy under competition in quantities: in other words, the inverse of the demand elasticity represents an upper bound for the size of the optimal export subsidy.

\subsubsection{The case of CES preferences}

The direct demand function derived from our usual CES preferences (12) is:

$$
D(p, \beta)=\frac{\bar{S} p^{-\theta}}{p^{1-\theta}+\beta}
$$

with $g(p)=p^{1-\theta}$. Under the optimal policy, the equilibrium price of the domestic firm must be $p=\theta c /(\theta-1)$, exactly as in the case of competition in 
quantities. Moreover, the foreign firms must sell at the higher price:

$$
p^{*}=\frac{\theta c \bar{S}}{(\theta-1)(\bar{S}-F)}
$$

The associated optimal subsidy to domestic production can be derived as:

$$
\tau_{H}=\frac{p}{\theta\left\{(1-F / \bar{S})^{\frac{1}{\theta}}[\bar{S} / \theta F+(\theta-1) / \theta]-1\right\}}>0
$$

which is again decreasing in the size of the international market.

\section{Applications of the EMS approach}

In this section we adopt the EMS approach to examine traditional trade issues. We start with an analysis of the role of multinationals active in international markets, then we move to the role of lobbying in affecting trade policy for international markets and finally we evaluate the impact of policies of indirect export promotion.

\subsection{Application I: Multinationals and FDIs}

Our modeling approach to global markets with endogenous market structures can be used for many investigations. One concerns the strategies of multinationals with superior technologies deciding the form of foreign direct investment (FDI) in international markets.

To evaluate the impact of FDIs by multinationals with lower production costs in a third market, we can apply our first Theorem, for which any exogenous change in the profit function of domestic firm is not going to affect the equilibrium strategies of all the other firms, but only their number. As a consequence, we can immediately evaluate the consequence of the entry of a multinational in a foreign market with a direct (greenfield) investment, which requires to build a new factory that produces at a lower marginal cost than the local competitors: such an entry would induce exit of other local firms. Contrary to this, the acquisition of a local firm with the same cost structure of the other local firms would not induce this effect. Therefore, one can verify that such a cross-broder acquisition would be preferred to the direct investment only if the fixed cost of the latter is high enough or the sinergies from the merger are high enough. In both cases, the investment would be profitable for the multinational firm, without changing the strategies of the other firms and (under homogenous goods and Cournot competition or under our examples of Bertrand competition) without affecting welfare in the importing country. 
We can summarize the main results of this application as follows:

Proposition 5. Under endogenous entry in the international market, a direct investment by a more efficient multinational firm or a cross-border acquisition of a less efficient local firm would not affect the strategies of the rivals and local welfare, but the first strategy would reduce the number of rivals and it would be chosen if the fixed cost of the investment or the sinergies from the merger are low enough.

Markusen and Stähler (2010) have analyzed this issue looking at linear Cournot models and comparing the results with exogenous and endogenous entry. In line with our results, they find that, with an exogenous market structure, a greenfield investment implies an increase in aggregate output and a decrease in output and profits of the local firm, but in the long run, when the market structure can be regarded as endogenous, aggregate output does not change and some local firms exit from the market, generating larger profits for the multinational compared to the fixed market structure. In case of an acquisition, Markusen and Stähler (2010) have assumed Nash bargaining in the merger: with a fixed market structure, the acquisition of a local firm reduces aggregate output and increases output and profits of the local firms, but with an endogenous market structure, additional entry reduces the profits for the multinational compared to the fixed market structure. In the same spirit, they have also analyzed the choice between FDIs and exports for the multinational. ${ }^{14}$

\subsection{Application II: Lobbying for production subsidies}

It is widely claimed that trade policy is often determined by lobbying activity of special interest groups rather than by welfare maximizing politicians. In this section we study the way in which firms that are targets for subsidies to domestic production in an integrated market can affect trade policy through rent-seeking activities (similar conclusions apply to the case of lobbying for import tariffs).

Define $C(\tau)=C[z(\tau), \beta(\tau), \tau]$ as a reduced form for the social cost of the policy, which we assume increasing and convex: for instance, in case of subsidies, this is the tax revenue necessary to finance them. The optimal policy studied

\footnotetext{
${ }^{14}$ Their main finding is that greenfield entry and exporting options are more attractive relative to acquisition when the local market structure adjusts to foreign entry through local entry or exit than when it is fixed. The entering foreign firm may do better or worse under endogenous entry versus a fixed market structure depending on its optimal choice under the latter assumption.
} 
in Section 4 is the one that maximizes $W(\tau)=S u+\bar{S} \Pi-C(\tau)$, and satisfies the first order condition $(d \Pi / d \tau) \bar{S}=C^{\prime}\left(\tau_{H}\right)$.

Here we want to extend this basic model to take into account the lobbying activity of the domestic firm (exporters represent a minoritarian but well organized part of the society). Following Grossman and Helpman (1994), the easiest way to endogenize lobbying is to imagine that the government chooses its policy to maximize a weighted average of welfare and firm's profits:

$$
\tau=\arg \max [(1-\lambda) W(\tau)+\lambda \bar{S} \Pi]=\arg \max \{\bar{S} \Pi+(1-\lambda)[S u-C(\tau)]\}
$$

where $\lambda$ is the weight given to the profits of the firm, which will be endogenized later. Given $\lambda$, the equilibrium policy satisfies the first order condition:

$$
\frac{d \Pi}{d \tau} \bar{S}=(1-\lambda) C^{\prime}(\tau)
$$

which delivers a subsidy $\tau_{H}(\lambda)$ increasing in $\lambda$, that is in the weight given by the politician to the firm's profits in its objective function, and equal to the optimal one if this weight is zero $\left(\tau_{H}(0)=\tau_{H}\right)$. However, as shown by our first Theorem and the analysis of Section 4, the equilibrium subsidy is not going to affect consumer surplus in any way: the outcome of the lobbying activity in markets with endogenous entry is to reduce entry of international firms and shift profits toward the domestic one without consequences for the utility of domestic consumers. In particular, if the revenue to finance the subsidy can be collected with lump sum taxes, the lobbying activity does not create any welfare loss, but a pure transfer of resources toward the domestic firm.

Let us look at lobbying for subsidies in the model with Cournot competition and homogeneous goods and general cost functions. Under endogenous entry, assuming that the elasticity of the marginal cost $\sigma=c^{\prime \prime}(x) x / c^{\prime}(x)>0$ is high enough to have an interior solution, the politico-economic equilibrium subsidy can be easily derived as a generalization of (31):

$$
\tau_{H}(\lambda)=\frac{p}{\varepsilon}\left[\frac{1+\lambda+\lambda \sigma(1-\varepsilon) / \varepsilon}{1-\lambda-\lambda \sigma}\right]
$$

When $\lambda=0$ we are back to the welfare maximizing production subsidy $\tau_{H}(0)=$ $p / \varepsilon$, which is a particular case of (31) when goods are homogenous, otherwise the equilibrium subsidy is larger and increasing in $\sigma$. Summing up:

Proposition 6. Under endogenous entry in an integrated market and lobbying by domestic producers, the politico-economic equilibrium subsidy is increasing in the weight that politicians give to domestic producers but does not affect domestic consumer surplus. 
Finally, the lobbying activity by the exporting firm determines $\lambda$, and this framework provides a simple way to understand the benefits of lobbying. If the cost of the lobbying activity to obtain a weight $\lambda$ in the objective function of the politician is $L(\lambda)$, which is assumed increasing and convex, the investment in lobbying will select $\lambda$ to maximize $\bar{S} \Pi-L(\lambda)$. The first order condition is $(d \Pi / d \tau) \bar{S} \tau_{H}^{\prime}(\tilde{\lambda})=L^{\prime}(\tilde{\lambda})$, and using (45) it allows us to derive a more informative expression for the equilibrium lobbying:

$$
\tilde{\lambda}=1-\frac{L^{\prime}(\tilde{\lambda})}{C^{\prime}\left[\tau_{H}(\tilde{\lambda})\right] \tau_{H}^{\prime}(\tilde{\lambda})}
$$

The right hand side contains the ratio between the marginal cost of lobbying for the exporting firm, and the product of the marginal cost of subsidization with the derivative of the policy with respect to $\lambda$, which is just the social marginal cost of lobbying.

Similar results can be derived for the case of competition in prices. The bottom line is that even if there is a strategic incentive to promote domestic output, lobbying activity induces excessive promotion. If this distortion is strong, a commitment to free trade may be still optimal for domestic welfare.

\subsection{Application III: Indirect trade promotion}

The general principles on the optimal subsidization of the domestic production can be applied to other policies which increase demand for the domestic products in an indirect way, for instance international advertising of domestic products, public support of domestic supplies abroad and so on. As before, the results depend crucially on the way a policy affects the marginal profitability, and generalize those found by Etro (2006, Prop. 3, p. 154) for general demandenhancing investments. ${ }^{15}$ In particular, when the policy increases the demand for the domestic goods (without making it too rigid), one can show the following result:

PROPOSITION 7. Under endogenous entry in the international market, overinvestment (underinvestment) in promotion of domestic production is always optimal with competition in quantities (prices).

The ambiguity of the direction of the optimal policy depends on the fact that demand enhancing policies have an impact on the strategic attitude of the domestic firms which depends on the form of competition.

\footnotetext{
${ }^{15}$ In our terminology, the results depend on the sign of $\Pi_{13}$ defined as the derivative of the marginal profits with respect to the investment in trade promotion.
} 
Other forms of indirect export promotion can affect the supply side. In a context of international trade, transport costs are crucial since the marginal cost of exports depend on them. The government can implement policies to reduce transport costs for all the exporting firms. A main example is given by investments in infrastructures for international communication, but more indirect examples include the establishment of easier business connections with other countries, the reduction of bureaucracy for export duties and even the development of trade unions and currency unions to reduce import tariffs and uncertainty costs related with the exchange rate. Applying the principles found by Etro (2006, Prop. 2, p. 153), one can show that there may or may not be a strategic incentive to reduce transport costs when there are barriers to entry abroad, but under endogenous entry this incentive always exists:

Proposition 8. Under endogenous entry in the international market, overinvestment in reduction of transport costs is always optimal.

Finally, even forms of the infant industry argument can be defended (only) under special circumstances on the basis of our theory: if initial overproduction can reduce production costs and create a comparative advantage in this sense, it may be optimal to close the domestic sector from the competition of international firms so as to develop a cost effective domestic industry able to compete in the international market in the future.

\section{Conclusion}

We studied international trade theory in the presence of endogenous market structures characterized by both strategic interactions and endogenous entry. The theoretical analysis has emphasized that globalization leads to lower prices and to fewer, but larger, firms. This increase welfare but leads to an inefficient organization of production in the global production. For this reason we have revisited the role of trade policy in the presence of endogenous entry in domestic and integrated markets with competition in prices and quantities. We have shown that the traditional bias in favor of a positive import tariff holds for a large country, but the role of the tariff is to reduce entry of foreign firms (rather than their individual production) and collect revenue to compensate for the price increase. The optimal tariff is decreasing in the ratio between the size of the domestic market and the fixed costs of entry. We have also analyze the optimal policy on the domestic production for an integrated market (when export subidies are forebidden), and we have shown that the bias in favor of taxes collapses: positive subsidies to domestic production are always optimal. Finally, we have argued that the analysis of international endogenous market 
structures can shed light on many other issues, including the political economy of trade policy, the role of multinationals and forms of indirect trade promotion.

\section{Appendix: Evidence on Market-size Effects}

In this Appendix we provide some microeconometric evidence in support of the EMSs approach, and we argue that this evidence is in line with one of its main implications for international trade theory, the effect of opening up to trade with new markets on the production structure, and in particular on the number of firms. ${ }^{16}$

In the text we have emphasized the different implications of the model of monopolistic behavior with endogenous entry à la Dixit and Stiglitz (1977) and Krugman (1980) and of the EMSs approach. A clear distinction emerges for the relation betwen the size of the market and the number of firms in each sector. Both the Krugman-Dixit-Stiglitz approach and the EMSs approach generate a positive correlation between market size and the number of firms, however the relation is linear in the former case and it is typically concave in the latter. This has a crucial implication: according to the Krugman-Dixit-Stiglitz framework with monopolistic behavior, it takes a market of double size to double the number of firms, while under competition in quantities and endogenous entry à la Brander (1981) the size of the market must be more than double for the number of firms to be twice as much. The modern empirical literature on EMSs has investigated the relation between market size and entry in local markets. The pathbreaking work in the field by Bresnahan and Reiss (1987) has studied professional and retail markets in small and isolated U.S. towns providing a certain support for the EMSs approach. Stronger evidence derives from the recent works by Manuszak (2002) and Campbell and Hopenhayn (2005) through the analysis of cross-sectional data at the industry level. Here we provide additional support through a more general panel data analysis looking at different industries over time.

We estimate the following structural relation between number of firms $n_{j t}$ in sector $j$ at time $t$ and the market size $S_{j t}$ of the same sector at the same time:

$$
\ln n_{j t}=\beta_{0 j}+\beta_{1} \ln S_{j t}+\varepsilon_{j t}
$$

where $\varepsilon_{j t}$ is an error term. The Krugman-Dixit-Stiglitz model implies $\beta_{1}=1$, as can be verified from (14), whose linearization is:

$$
\ln n=\ln S-\ln F-\ln \theta
$$

\footnotetext{
${ }^{16}$ This Appendix is entirely based on joint work with Dirk Czarnitzki. I share with him the merits, while I am only responsible for the mistakes.
} 


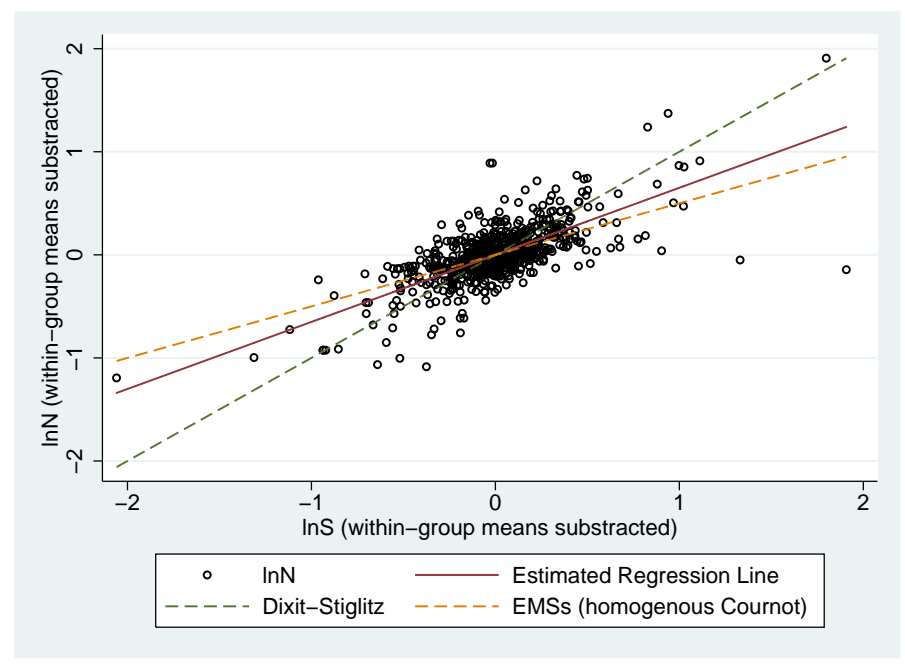

Figure 1: Number of firms and Market Size for German industries (from regressions). NACE 3-digit level.

Bertrand competition with endogenous entry leads to approximately the same results. Instead, Cournot competition with endogenous entry à la Brander (1981) implies $\beta_{1} \in[0.5,1)$, with a coefficient that should decrease with the degree of substitutability between products. In particular, in case of homogenous goods we have $\beta_{1}=0.5$, as can be verified from (15), ${ }^{17}$ whose linearization is:

$$
\ln n=0.5(\ln S-\ln F)
$$

On this basis we can test the Krugman-Dixit-Stiglitz hypothesis and compare it with the predictions of the Cournot model.

One can also check the relation between concentration and market size. Common indexes of market concentration can be highly criticized as a measure of market power, nevertheless we used the HHI of concentration for robustness analysis. This index corresponds to the sum of the squared market shares, and in the case of symmetric competition it becomes $H H I_{j t}=\left(1 / n_{j t}\right) \cdot 1000$, there-

\footnotetext{
${ }^{17}$ Notice that a strategic model in which mark ups depend on the number of firms (negatively) and on the market size (positively) in more general ways could rationalize $\beta_{1}<0.5$. Endogenizing the fixed costs of entry, one could even reach a non-monotone relation between size and number of firms à la Sutton (1991). Moroever, one could interpret market structure indeterminacy associated with perfect competition with $\beta_{1}=0$ (no relation between size and number of firms).
} 
fore we would expect an inverse relation compared to that found for the number of firms.

Our preliminary investigation of the relation between market size and number of firms is based on a panel of industry level data for the German manufacturing sector. The data stem from the bi-annual official publications of the German Monopolies Commission, that publishes regularly concentration statistics for competition policy purposes. This data source contains the number of firms, total industry sales, which we adopt as a measure of market size, and the HHI index for German manufacturing for different aggregations of the European standard industry classification called NACE. In the following, we utilize data at the NACE 3-digit level, which results in 102 different manufacturing industries. We have bi-annual data between 1991 and 2003. Table 1 shows the summary statistics of the number of firms, $n_{j t}$, the total industry sales, $S_{j t}$, that we use as market size variable, and the Herfindahl Index, $H H I_{j t}$.

Table 1. Descriptive Statistics (711 observations, 102 industries)

\begin{tabular}{lcccc}
\hline & Mean & Std. dev. & Min. & Max. \\
\hline$n_{j t}$ & 387 & 540 & 1 & 3851 \\
$S_{j t}$ & 22456.38 & 34878.98 & 31.99 & 38569.31 \\
$H H I_{j t}$ & 84.05 & 141.75 & 3.15 & 2431.14 \\
\hline
\end{tabular}

We estimate three different panel models. First, we estimate a pooled crosssectional OLS regression (POLS) where we implicitly assume that $\beta_{0 j}=\beta_{0}$ for any $j$. This is then relaxed by estimating two fixed effects models. We allow $\beta_{0 j}$ to be industry specific by applying the within panel regression (FE: Within) and by estimating a first-difference model (FE: FD). The results are displayed in Table 2. Standard $F$-tests confirm the presence of industry-specific $\beta_{0 j}$, so that the POLS models are rejected. Consequently, we should turn our attention to the fixed effects models. In the regression concerning the number of firms, we find that the slope of market size is positive and significant in both the within and the FD regression. The Krugman-Dixit-Stiglitz hypothesis that $\beta_{1}=1$ is clearly rejected in both models, with respectively $F=22.9^{* * *}$ and $27.69^{* * *}$.

Fig. 1 plots the $(\log )$ number of firms of the industries against the $(\log )$ sales per industry, here on the basis of the within regression. The $45^{\circ}$-dashed line represents the hypothetical relation between number of firms and size that emerges from the Krugman-Dixit-Stiglitz approach $\left(\beta_{1}=1\right)$, while the flatter dashed line is the relation that emerges from the EMSs approach in case of Cournot competition with homogenous goods $\left(\beta_{1}=0.5\right)$. We expect that the data lie between these two extreme predictions, and this is exactly what we find out. The Krugman-Dixit-Stiglitz approach is rejected, meaning that there is a robust positive but less than proportional relation between the size of the 
market and the number of firms. The estimates for $\beta_{1}$ in the within and firstdifference model are respectively $\beta_{1}=0.650$ (the case of Fig. 1 ) and $\beta_{1}=0.507$ (which in Fig. 1 could not be distinguished from the flatter dashed line): this suggests that the EMSs model with Cournot competition and homogenous goods is a better approximation to the data (indeed, the hypothesis $\beta_{1}=0.5$ cannot be rejected in both models). The results are confirmed when we group firms in macrosectors (ICT, machinaries, chemicals, paper, metal, food- and textilerelated industries) with the Krugman-Dixit-Stiglitz hypothesis rejected always except for textile-related sectors. Finally, notice that even without controlling for other variables, our basic results are quite powerful, with $R^{2}$ around $50 \%{ }^{18}$

Table 2. Regression Results

\begin{tabular}{|c|c|c|c|c|c|c|}
\hline & \multicolumn{2}{|c|}{ POLS } & \multicolumn{2}{|c|}{ FE: Within } & \multicolumn{2}{|c|}{ FE: FD } \\
\hline & Coef. & (Std. err.) & Coef. & (Std. err.) & Coef. & (Std. err.) \\
\hline \multicolumn{7}{|c|}{ Regression of $\ln N_{j t}$ on $\ln S_{j t}$} \\
\hline$\beta_{1}$ & 0.611 & $(0.07)^{* * *}$ & 0.650 & $(0.07)^{* * *}$ & 0.507 & $\overline{(0.09)^{* * *}}$ \\
\hline Obs. & & 711 & & 711 & & 609 \\
\hline$R^{2}$ & & 0.45 & & 0.56 & & 0.43 \\
\hline
\end{tabular}

Note: Each regression includes a full set of time dummies. They are always significant at the $5 \%$ level. $* * *(* *, *)$ indicate a significance level of $1 \%(5 \%, 10 \%)$.

The regressions on the HHI show a weaker relation with market size, but they nevertheless identify a negative slope much lower than one, again in contradiction with the Dixit-Stiglitz hypothesis.

We have also verified the robustness of our results with different datasets, always for the German manufacturing sector, obtaining similar patterns. Fig. 2 reports the basic within panel regression based on data at the NACE 4digit level from the annual "Kostenstrukturerhebung" published by the German Federal Statistical Office (235 groups bewteen 1995 and 2006 for a total of 2695 observations). The results are in line with the earlier ones, except for one difference: when we look at more disaggregated data, the estimated coefficient $\beta_{1}$ decreases, here to $\beta_{1}=0.40$. This may support another implication of the EMSs approach: a higher degree of substitutability, that we find at more disaggregated levels in the data, changes the relation between market size and number of firms and reduces the associated coefficient.

This preliminary investigation supports the idea that an increase in the size of a market, due for instance to the integration with a formerly separate market, leads to a less than proportional increase in the number of firms, to lower mark ups and to a larger production for each firm. Further research should try to

\footnotetext{
${ }^{18}$ The results are not driven by the dynamic framework: similar coefficients emerge in crosssectional regressions based on each single year.
} 


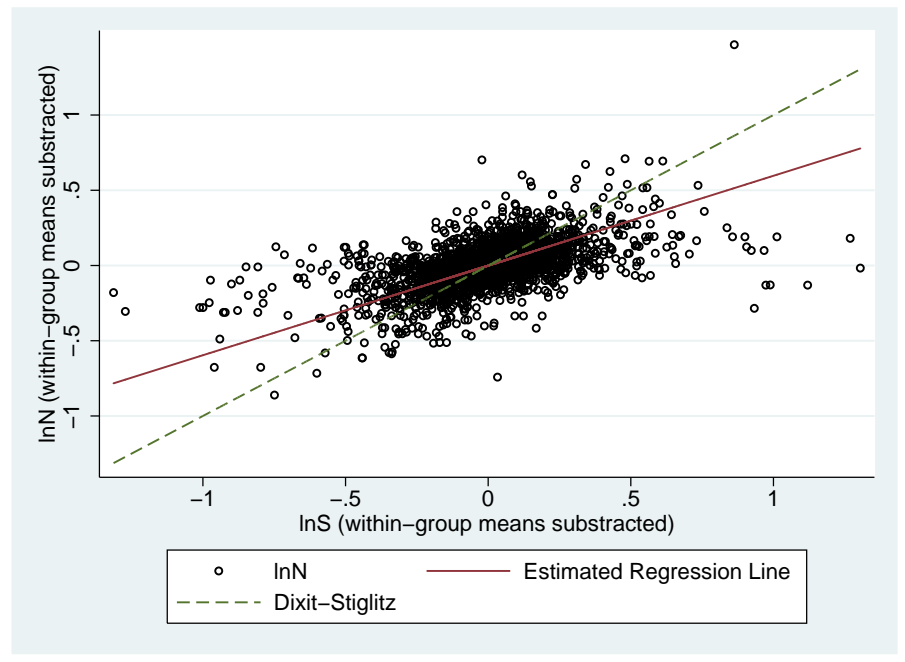

Figure 2: Number of firms and Market Size for German industries (from regressions). NACE 4-digit level.

verify whether these results are supported in other countries or datasets, and, most of all, try to check directly the impact of different measures of openness on the structure of markets.

\section{REFERENCES}

Atkeson, Andrew and Ariel Burnstein, 2008, Pricing to Market, Trade Costs, and International Relative Prices, The American Economic Review, 98, 5, 1998-2031

Atkeson, Andrew and Ariel Burnstein, 2010, Innovation, Firm Dynamics, and Internationa Trade, Journal of Political Economy, 118, 3, 433-84

Anderson, Simon, Nisvan Erkal and Daniel Piccinin, 2010, Aggregative Games with Entry, mimeo, University of Virginia

Bhattacharjea, Aditya, 1995, Strategic Tariffs and Endogenous Market Structures: Trade and industrial Policies under Imperfect Competition, Journal of Development Economics, 47, 287-312

Brander, James, 1981, Intra-industry Trade in Identical Commodities, Journal of International Economics, 11, 1, 1-14

Brander, James and Paul Krugman, 1983, A Reciprocal Dumping Model of International Trade, Journal of International Economics, 15, 313-21 
Brander, James and Barbara Spencer, 1985, Export Subsidies and International Market Share Rivalry, Journal of International Economics, 16, 83-100

Bresnahan, Timothy and Peter Reiss, 1987, Do Entry Conditions Vary across Markets?, Brookings Papers on Economic Activity, 3, 833-81

Campbell, Jeffrey and Hugo Hopenhayn, 2005, Market Size Matters, Journal of Industrial Economics, 53, 1, 1-25

De Santis, Roberto and Frank Stahler, 2004, Endogenous Market Structures and the Gains from Foreign Direct Investment, Journal of International Economics, 64, 545-65

Devereux, Michael, Allen Head and Beverly Lapham, 1996, Aggregate Fluctuations with Increasing Returns to Specialization and Scale, Journal of Economic Dynamics and Control, 20, 627-56

Dixit, Avinash, 1984, International Trade Policy for Oligopolistic Industries, The Economic Journal, 94, 1-16

Dixit, Avinash and Joseph Stiglitz, 1977, Monopolistic Competition and Optimum Product Diversity, The American Economic Review, 67, 297-308

Eaton, Jonathan and Gene Grossman, 1986, Optimal Trade and Industrial Policy under Oligopoly, Quarterly Journal of Economics, 101, 386-406

Etro, Federico, 2006, Aggressive Leaders, The RAND Journal of Economics, 37, $1,146-54$

Etro, Federico, 2010a, Endogenous Market Structures and the Optimal Financial Structure, Canadian Journal of Economics, 43, 4, 1333-52

Etro, Federico, 2010b, Endogenous Market Structures and Contract Theory, mimeo, University of Venice, Ca' Foscari

Etro, Federico, 2011, Endogenous Market Structures and Strategic Trade Policy, International Economic Review, in press

Etro, Federico and Andrea Colciago, 2010, Endogenous Market Structure and the Business Cycle, The Economic Journal, in press

Grossman, Gene and Elhanan Helpman, 1994, Protection for Sale, The American Economic Review, 84, 4, 833-50

Helpman, Elhanan and Paul Krugman, 1989, Trade Policy and Market Structure, MIT Press

Horstmann, Ignatius and James Markusen, 1986, Up the Average Cost Curve: Inefficient Entry and the New Protectionism, Journal of International Economics, 20, 225-47

Horstmann, Ignatius and James Markusen, 1992, Endogenous Market Structures in International Trade (Natura Facit Saltum), Journal of International Economics, 32, 109-29

Erkal, Nisvan and Daniel Piccinin, 2010, Cooperative R\&D under Uncertainty 
with Free Entry, International Journal of Industrial Organization, 28, 1, 7485

Kováč, Eugen, Viatcheslav Vinogradov and Krešimir Žigić, 2009, Technological Leadership and the Persistence of Monopoly under Endogenous Entry, Journal of Economic Dynamics 83 Control, 34, 8, 1421-41

Krugman, Paul, 1979, Increasing Returns, Monopolistic Competition and International Trade, Journal of International Economics, 9, 469-79

Krugman, Paul, 1980, Scale Economies, Product Differentiation, and the Pattern of Trade, The American Economic Review, 70, 950-9

Lahiri, Sajal and Yoshiyasu Onu, 1995, The Role of Free Entry in an Oligopolistic Heckscher-Ohlin Model, International Economic Review, 36, 3, 609-24

Lerner, Abba, 1934, The Diagrammatic Representation of Demand Conditions in International Trade, Economica, 1, 319-34

Long, Ngo van, Horst Raff and Frank Stähler, 2009, Innovation and Trade with Heterogeneous Firms, mimeo, McGill University

Mankiw, Gregory and Michael Whinston, 1986, Free Entry and Social Inefficiency, The RAND Journal of Economics, 17, 1, 48-58

Manuszak, Mark, 2002, Endogenous Market Structure and Competition in the 19th Century American Brewing Industry, International Journal of Industrial Organization, 20, 673-932

Markusen, James and Frank Stähler, 2010, Endogenous Market Structure and Foreign Market Entry, NBER WP 15530

Melitz, Marc, 2003, The Impact of Trade on Intra-Industry Reallocations and Aggregate Industry Productivity, Econometrica, 71, 6, 1695-725

Neary, Peter, 2010, Two and a Half Theories of Trade, World Economy, 33, 1, 1-19

Peretto, Pietro, 1996, Sunk Costs, Market Structure and Growth, International Economic Review, 37, 895-923

Peretto, Pietro, 2003, Endogenous Market Structure and the Growth and Welfare Effects of Economic Integration, Journal of International Economics, 60, $177-201$

Sutton, John, 1991, Sunk Costs and Market Structure, MIT Press

Venables, Anthony, 1985, Trade and Trade Policy with Impefect Competition: the Case of Identical Products and Free Entry, Journal of International Economics, 19, 1-19 